\title{
SNAP19 mediates the assembly of a functional core promoter complex (SNAP ) shared by RNA polymerases II and III
}

\author{
R. William Henry, ${ }^{1,3}$ Vivek Mittal, ${ }^{1,2}$ Beicong Ma, ${ }^{1,2}$ Ryuji Kobayashi, $^{1}$ and Nouria Hernandez ${ }^{1,2,4}$ \\ ${ }^{1}$ Cold Spring Harbor Laboratory and ${ }^{2}$ Howard Hughes Medical Institute, Cold Spring Harbor, N ew Y ork 11724 USA
}

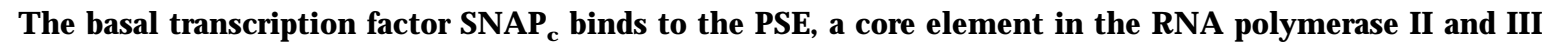
human snRNA promoters. SNAP ${ }_{c}$ contains at least four subunits, but it has not been possible to assemble a fully defined recombinant SNAP ${ }_{c}$. Here we reconstitute SNAP $_{c}$ from five recombinant subunits, SNAP43, SNAP45, SNAP50, SNAP190, and a newly identified subunit, SNAP19. This recombinant complex binds specifically to the PSE and directs both RNA polymerase II and III snRNA gene transcription. Thus, the same core SNAP $_{c}$ nucleates the assembly of two classes of initiation complexes.
\end{abstract}

[Key Words: SNAP ; human snRNA promoters; RNA polymerases; transcription]

Received May 21, 1998; revised version accepted July 17, 1998.

Although consi derable effort has focused on understanding RN A polymerase II transcription from mRN A-type promoters and RNA polymerase III transcription from 5S- and tRNA-type promoters, a significant portion of RNA polymerase II and III transcriptional initiation events is directed by snRN A-type promoters ( $D$ ahlberg and Lund 1988). Unravel ing the mechanisms that govern snRNA gene transcription is, therefore, integral to an understanding of the gl obal network of RNA polymerase II and III transcription.

For most promoters, RNA polymerase specificity is determined by different promoter elements that recruit distinct DNA-binding basal transcription complexes. Thus, the RNA polymerase II mRNA promoters recruit the TATA box-binding protein (TBP)-containing complex TFIID, and this results in the subsequent recruitment of TFIIB (as well as other general transcription factors) and RN A polymerase II (Orphanides et al. 1996). The 5S- and tRN A-type RNA polymerase III promoters recruit TFIIIC, either di rectly or through TFIIIA, and this results in the recruitment of the TBP-containing complex TFIIIB and RNA polymerase III (Geiduschek and Kassavetis 1992). In contrast, the RN A polymerase II and III human SnRNA promoters contain a similar proximal sequence element (PSE), which is involved in directing transcription by both RNA polymerases. RNA polymerase III transcription is specified by the presence (and

\footnotetext{
${ }^{3}$ Present address: Department of Biochemistry, Michigan State University, East Lansing Michigan 48824-1319 USA.

${ }^{4}$ Corresponding author.

E-MAIL hemande@cshl.org FAX (516) 367-6801.
}

RNA polymerase II transcription by the absence) of an adjacent TATA box (Mattaj et al. 1988; Lobo and Hernandez 1989). The PSE and the TATA box are the only known core elements involved in both RN A polymerase II and III transcription. These observations raise the intriguing possibility that the PSE in the RNA polymerase II and III snRNA promoters recruits the very same basal transcription factor.

The PSE is recognized by the snRN A activating protein complex (SNAP c $_{\text {c }}$ (Sadowski et al. 1993), a basal transcription factor also known as PTF (Murphy et al. 1992). Previous purifications of SNAP (Henry et al. 1995) and PTF (Yoon et al. 1995), as well as isolation of cDNA clones (Henry et al. 1995, 1996; Bai et al. 1996; Sadowski et al . 1996; Y oon and Roeder 1996; Wong et al. 1998) identified four subunits with apparent molecular masses of 43, 45, 50, and $\sim 200 \mathrm{kD}$. In addition, significant but substoichiometric amounts of TBP copurified extensively with PSE-binding activity (Henry et al. 1995). However, the four recombinant subunits, with or without TBP, are insufficient to reconstitute a SNAP complex with DNA-binding and transcriptional activities similar to endogenous $\mathrm{SNAP}_{\mathrm{c}}$ (Wong et al. 1998). Thus, it has not been possible to determine whether the PSE in the RN A polymerase II and III SnRNA promoters is recognized by the same complex or by $\mathrm{SN} \mathrm{AP}_{\mathrm{C}}$ variants that are responsible for nucleating different transcription initiation complexes.

Here we demonstrate that in addition to the previously characterized subunits, a small 19-kD protein, SNAP19, is also a member of the endogenous SNAP complex. SN AP19 is a novel protein of 98 amino acids 
characterized by an amino-terminal leucine zipper motif and a carboxy-terminal glutamic acid-rich region. Like the other members of SNAP ${ }_{C}$ SNAP19 is required for snRNA gene transcription by both RNA polymerases II and III. In coimmunopreci pitation assays, SN AP19 interacts with SN AP190. Importantly, this interaction allows the association of both SNAP43 and SNAP50, which does not occur in the absence of SNAP19. Therefore, SN AP19 is essential for mediating the assembly of a core SN AP compl ex containing SN AP19, SN AP43, SN AP45, SNAP50, and SNAP190. Recombinant complexes assembled with all five $S N A P_{c}$ proteins bind effectively to DNA in a PSE-specific manner and function to restore RNA polymerase II and III transcriptional activity in nuclear extracts that have been depleted of endogenous SN AP ${ }_{C}$. These results identify the same core TN AP $_{c}$ as a basal transcription factor recruited by two classes of promoters, the human RNA polymerase II and III snRNA promoters.

\section{Results}

p19 is a member of SNAP

Because we could not assemble a recombinant SN AP complex from SN AP43, SN AP45, SN AP50, and SN AP190, we suspected the existence of an unidentified, essential subunit. During biochemical fractionation of $\mathrm{SNAP}_{c}$ a small polypeptide with an apparent molecular mass of 19 kD copurified extensively with PSE binding and U 1 transcriptional activity (R.W. Henry, unpubl.). Microsequence of this material, previously thought to be a proteolytic degradation product, yielded three peptide sequences not present in the known $\operatorname{SNAP}_{\mathrm{c}}$ subunits. These new sequences were used to search expressed sequence tag (EST) databases for corresponding CDNA clones. Candidate sequences were identified and used to assemble a complete ORF, which was then confirmed by the sequencing of PCR products generated with appropriate primers from CDNA synthesized from total RNA. As shown in Figure 1, the resulting open reading frame (ORF) contains the three peptides, which encompass amino acids 11-19, 20-30, and 31-41 (shaded underlines), and encodes a novel protein of 98 amino acids with a predicted molecular mass of $11.4 \mathrm{kD}$. We refer to this protein as SNAP19. SNAP19 contains a potential leucine zipper motif at its amino terminus (amino acids 1-36) and a notable acidic region of 10 glutamic acid residues at its carboxyl terminus (amino acids 86-95). The initiation codon is preceded by a stop codon (data not shown), suggesting that this ORF encodes the fulllength protein.

Synthetic peptides corresponding to the amino (amino acids 1-13, p19N pep) and carboxyl (amino acids 82-98, p19C pep) termini of SN AP19 (Fig. 1, solid underlines) were used to raise rabbit polyclonal antisera. These antisera were tested for their ability to recognize biochemically purified HeLa cell $\mathrm{SNAP}_{\mathrm{c}}$ in an electromobility shift assay (EMSA), and the results are shown in Figure 2. SN AP ${ }_{c}$ bound specifically to the PSE (cf. Iane 2 to lane 1 ).

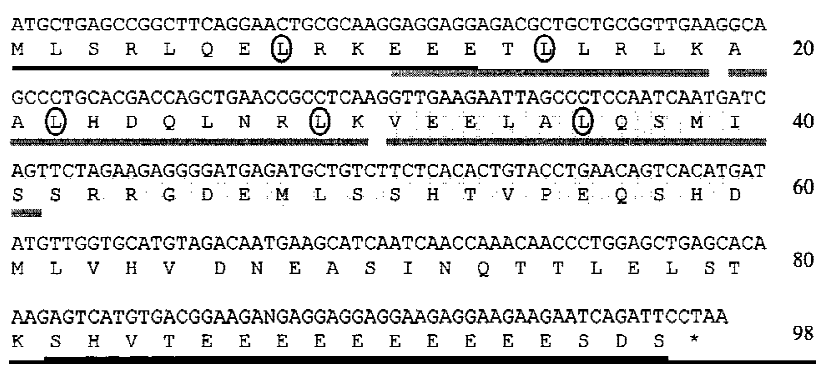

Figure 1. Nucleotide sequence and predicted amino acid sequence for SN AP19. The shaded underlines indicate the peptides microsequenced from biochemically isolated $\mathrm{SNAP}_{\mathrm{c}}$; (open circles) potential leucine zipper motif; (solid underlines) synthetic peptides used to raise rabbit polyclonal antibodies. The shaded amino acids are absent in some cDN As, probably as a result of alternative splicing, but the observation that part of this amino acid sequence is present in one of the three microsequenced peptides suggests that the larger form of the protein is present in biochemically purified $\mathrm{SNAP}_{\mathrm{C}}$.

Addition of anti-SN AP19 (carboxy-terminal) antibodies (lane 3) but not preimmune serum (lane 10) retarded the SN AP ${ }_{c}-P S E$ complex, and this effect could be inhibited by preincubation of the antibodies with increasing amounts of the peptide used to raise the antibody (lanes 4-6) but not with similar amounts of a nonspecific peptide (lanes 7-9). Thus, the 19-kD protein is indeed a member of SN AP ; hence, its name.

\section{SNAP19 is required for snRNA gene transcription} by RNA polymerases II and III

To determine whether SN AP19 is required for transcription of snRN A genes by both RNA polymerases II and III or whether it might be part of a complex dedicated to transcription by only one of these two polymerases, we used rabbit preimmune or anti-SN AP19 antibodies to deplete whole cell extracts. First, the effects of the depletions on levels of SNAP43 were determined by immunoblotting. As shown in Figure 3A, there was little difference in the amount of the SNAP43 component of $\mathrm{SNAP}_{\mathrm{c}}$ present in untreated whole cell extract (lane 1), and extracts treated with preimmune antibody beads (lane 2) or with anti-SNAP19 antibody beads preincubated with the peptide used to raise the antibody (lane 7). However, SNAP43 was efficiently immunodepleted when extracts were treated with anti-SN AP19 antibody beads (lanes 3-5) or anti-SN AP19 antibody beads preincubated with the nonspecific peptide (lane 6). Thus, immunodepl etion with anti-SN AP19 antibodies resulted in efficient depletion of another member of the SN AP complex, SN AP43. These results suggest that SN AP43 is not associated with any other non-SN AP19-containing complexes in the cell and that $\mathrm{SNAP}_{\mathrm{C}}$ is removed effectively by SN AP19 immunodepletion.

The depleted extracts were tested for their ability to support in vitro transcription of the $U 1$ snRN A gene by RNA polymerase II and the U6 SnRNA gene by RNA polymerase III. We also tested the depleted extracts for 


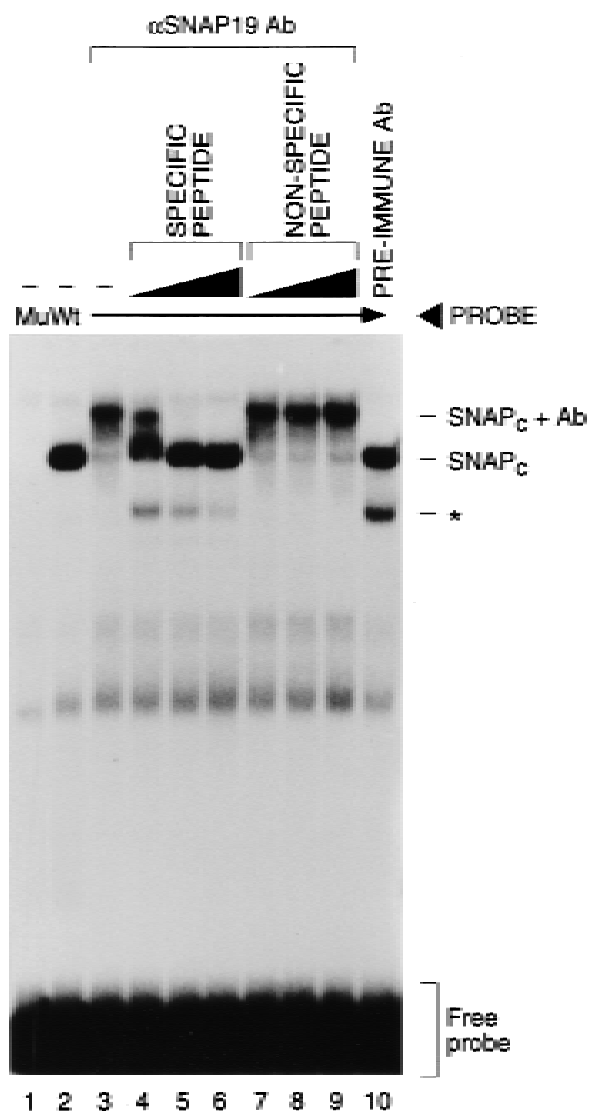

Figure 2. SNAP19 is a component of SNAP . Anti-SNAP19 antibodies supershift $\mathrm{SN} \mathrm{AP}_{\mathrm{c}}$ bound to DNA. EMSAs were performed with a biochemically purified $\mathrm{SNAP}_{\mathrm{C}}$-containing fraction [3 $\mu \mathrm{l}, 0.25 \mu \mathrm{g} / \mathrm{ml}$, mono Q fraction (Henry et al. 1995)] and mutant PSE (lane 1) or wild-type PSE (lanes 2-10) probes as described previously (Sadowski et al. 1993). Lanes 3-9 contained $0.3 \mu \mathrm{l}$ of anti-SN AP19 serum (anti-p19Cpep); lanes 4-6 contained $0.1,0.3$, and $1.0 \mu \mathrm{l}$, respectively, of specific peptide (p19C pep: $10 \mu \mathrm{g} / \mu \mathrm{l}$ ); and lanes 7-9 contained similar amounts of a nonspecific peptide (p19N pep). Lane 10 contained $0.3 \mu \mathrm{l}$ of rabbit preimmune serum. The band labeled with a an asterisk represents a proteolytic degradation product of $\mathrm{SN} \mathrm{AP}_{\mathrm{C}}$.

transcription directed by the adenovirus 2 ( $\mathrm{Ad} 2)$ major late promoter (AdML), a typical RNA polymerase II mRN A-type promoter, and by the Ad2 VAI promoter, a typical gene-internal RNA polymerase III promoter. As shown in Figure 3B, all four promoters directed efficient transcription in untreated extract or extract treated with preimmune antibody beads (lanes 1,2). In addition, neither RNA polymerase II transcription from the AdML promoter (top panel) nor RN A polymerase III transcription from the Ad2 VAI promoter (bottom panel) was significantly affected by $\mathrm{SNAP}_{\mathrm{c}}$ depletion with antiSN AP19 antibody beads or any of the conditions tested in this assay. Therefore, SN AP19 apparently is not involved in transcription of these genes. In contrast, RN A polymerase II transcription from the U1 snRNA promoter was reduced strongly in extracts treated with increasing levels of anti-SN AP19 antibody beads (second panel, lanes 3-5), whereas in the same lanes, transcrip- tion of a readthrough transcript (labeled RT), which probably results from cryptic mRN A-type promoters located within vector sequences (Sadowski et al. 1993), was not affected. Similarly, RNA polymerase III transcription from the U 6 snRN A promoter was decreased in extracts treated with anti-SN AP19 antibody beads (third panel). The inhibitory effect of the anti-SN A P19 antibody beads was specific because preincubation of the antibodies with the peptide used to raise the antiserum (p19Cpep, lane 7) but not a nonspecific peptide (p19N pep, Iane 6) reduced or prevented the inhibition of transcription.

A

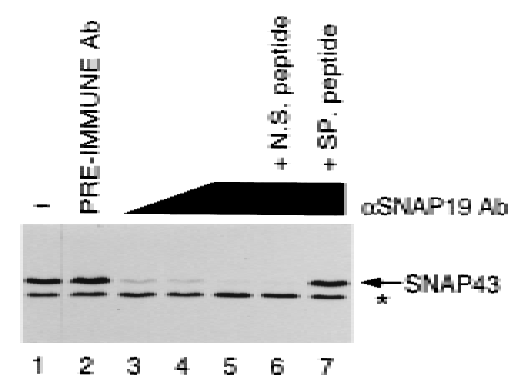

B
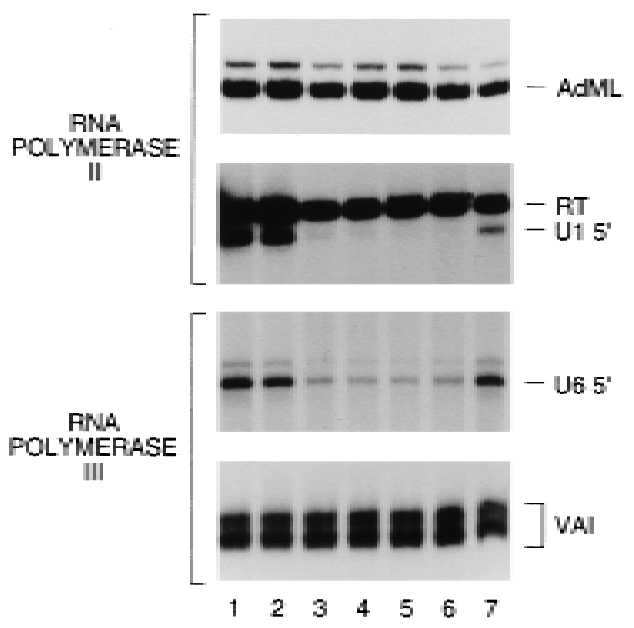

Figure 3. SN AP19 is required for human snRN A transcription by both RN A polymerases II and III. (A) Anti-SN AP43 immunobl ot analysis of depleted extracts. The samples in the various lanes correspond to $7 \mu \mathrm{l}$ of HeLa whole cell extract (lane 1), $10-\mu$ aliquot of extract depleted with a constant amount of beads consisting of only preimmune antibody beads (lane 2), preimmune antibody beads plus anti-SN AP19 antibody beads at 3:1 (lane 3) and 1:1 (lane 4) ratios, or only anti-SN AP19 antibody beads (lanes 5-7). In lanes 6 and 7, the immunodepletions were performed in the presence of $5 \mu \mathrm{g}$ of nonspecific (p19N pep) or specific (p19C pep) peptide, respectively. The band label ed with an asterisk corresponds to an unidentified cross-reacting protein and was used as a loading control. (B) The same extracts analyzed in A were tested for their ability to support in vitro transcription from the RN A polymerase II AdML (top panel) and U 1 snRNA (second panel) promoters, and the RN A polymerase III U6 snRN A (third panel), and Ad2 VAI (bottom panel) promoters. The correctly initiated transcripts are label ed AdM L, U 1 5', U $65^{\prime}$, and VAI, respectively. Readthrough transcripts from cryptic mRN A-type promoters in the U 1 transcription experiment (Sadowski et al. 1993) are labeled RT. 
These results suggest that SNAP19 itself or SNAP19associated subunits are required for both RNA polymerase II and III snRNA gene transcription.

\section{SNAP19 mediates assembly of a core $\mathrm{SNAP}_{\mathrm{C}}$}

The precise architecture of $\mathrm{SNAP}_{\mathrm{c}}$ is unknown. We showed previously that SN AP43 and SN AP50 associate (Henry et al. 1996) and that SN AP190 and SN AP45 associate (Wong et al. 1998), to form SNAP43/50 and SN AP190/ 45 protein pairs. However, we were unable to demonstrate any strong interactions between proteins in the different pairs. The identification of SNAP19 prompted us to test whether SN AP19, together with the four previously identified $\mathrm{SNAP}_{\mathrm{c}}$ components, could form a complete complex. Pair-wise studies of SN AP19 association with the other four SNAP components showed that SNAP19 can associate on its own with SN AP190 but not with SN AP43, SN AP45, or SNAP50 (data not shown). We then performed an in vitro cotranslation reaction containing all five subunits and used this material in a coimmunoprecipitation experiment with anti-SN AP43 antibodies. The results are shown in Figure $4 A$. Strikingly, in contrast to our previous experiments in which SN A P19 was missing (Wong et al. 1998), when all five subunits were cotranslated (lane 2), each subunit was efficiently immunoprecipitated by the anti-SN AP43 antibodies (lane 8). This suggests that in the presence of SN AP19, a complex containing all five subunits can be assembled, as shown schematically in Figure 4B (top panel).

To gain a better understanding of the architecture of SN AP complex, we performed cotranslations in which only SN AP19 (Fig. 4A, Iane 3), SN AP45 (lane 4), SN AP50 (lane 5), or SN AP190 (lane 6) had been omitted out of the five $\mathrm{SN} \mathrm{AP}_{c}$ subunits. As a control for anti-SN AP43 antibody specificity, SNAP43 was also omitted from one reaction (lane 7). Strikingly, when SN AP19 was omitted, neither SN AP190 nor SN A P45 was recovered in the antiSN AP43 immunoprecipitation (lane 9; see also Fig. 4B, panel labeled -SNAP19). Thus, in the absence of SN AP19, SN AP43 could only interact with SN AP50 in this assay, consistent with our previous results (Henry et al. 1996). When SN A P45 (Fig. 4A, Iane 10) or SN AP50 (lane 11) was omitted, all of the remaining subunits were coimmunopreci pitated with SN A P43, suggesting that, as observed before and as illustrated in Figure 4B, SN AP45 interacts strongly only with SN AP190 and SN AP50 in-

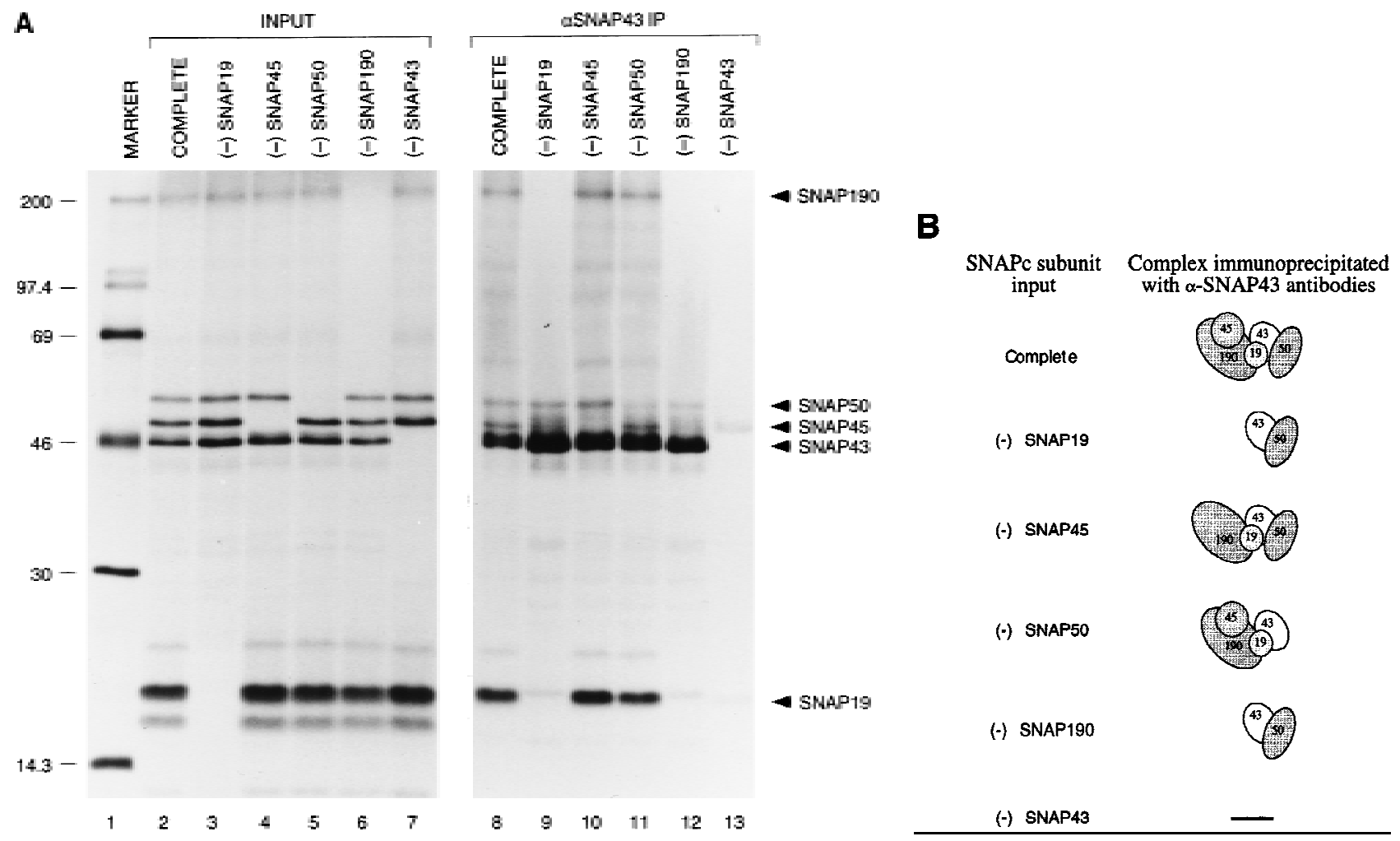

Figure 4. $\mathrm{SNAP} 19$ is essential for assembly of $\left.\mathrm{SNAP}_{\mathrm{c}} \cdot{ }^{35} \mathrm{~S}\right] \mathrm{M}$ ethioninelabeled SN AP subunits were cotranslated in rabbit reticulocyte lysates. The cotranslated products were used for immunoprecipitations with anti-SN AP43 antibodies, and the immunopreci pitates were fracti onated by $15 \%$ SDS-PAGE. Radiolabel ed proteins were detected by autoradiography. (Lane 1 ) Protein size markers; (lanes $2-7) 10 \%(1 \mu l)$ of the input materials used for the coimmunopreci pitations. In Iane 2, all five proteins were cotranslated; in lanes 3-7, one $\mathrm{SN} \mathrm{AP}_{\mathrm{c}}$ subunit was omitted in turn as indicated above the lanes. (Lanes 8-13) Immunoprecipitated proteins. The identity of each full-length protein is indicated. N ote that the weak band migrating very slightly ahead of SN AP50 in lane 11 was not reproducibly observed but is probably a proteolytic breakdown product of SN AP190. (B) Schematic representation of the anti-SN AP43 immunoprecipitation results. The stoichiometry of the various subunits is not known. 
teracts strongly only with SN A P43. When SN AP190 was omitted, neither SN AP19 nor SN AP45 was immunoprecipitated with the SN AP43/SN AP50 protein pair (lane 12). And when SN AP43 was omitted, no proteins were immunopreci pitated with the anti-SN AP43 antibody, as expected, except for weak background bands in the 45- to 50-kD range (lane 13). Thus, the coimmunopreci pitation results obtained with just pairs of in vitro-translated SN AP $_{\mathrm{c}}$ subunits (Henry et al. 1996; Wong et al. 1998; data not shown) are entirely consistent with those obtained when four of the five $\mathrm{SNAP}_{\mathrm{C}}$ subunits are present in the starting material, suggesting that individual protein-protein interactions detected in this assay accurately reflect protein-protein interactions occurring within the SN AP complex.

Together, these observations provide us with a detailed view of the architecture of the SN AP complex (Fig. $4 \mathrm{~B}$, top panel). Although the stoichiometry of the various subunits is not known, the results suggest that SN AP190 forms a backbone on which SN AP45 and SN AP19 can assemble directly and independently. SN AP19 is essential for the subsequent assembly of SNAP43 with SN AP190, perhaps because SN AP19 bridges the two proteins. The observation that SNAP43 does not interact with SN AP19 in a pairwise combination suggests, however, that SN AP43 is involved in weak protein interactions with both SN AP19 and SN AP190, only the sum of which is sufficient to promote coimmunoprecipitation in this assay. SNAP50 assembles with the complex via interactions with SNAP43. Consistent with this view of the complex, we can assemble a trimeric complex containing SNAP190, SNAP19, and SNAP43 (data not shown).

Recombinant SNAP ${ }_{C}$ mediates transcription by both RNA polymerases II and III

The observation that in the presence of SNAP19, all $\mathrm{SNAP}_{\mathrm{C}}$ subunits could be coimmunoprecipitated with SN AP43 suggested that we might be able to assemble a functional SNAP complex from recombinant subunits $\left(r S N A P_{c}\right)$. We therefore coexpressed the five SN AP ${ }_{C}$ subunits in a baculovirus expression system. As a control, we also coexpressed all $\mathrm{SNAP}_{\mathrm{c}}$ subunits except SN AP190. The resulting complexes were then purified by immunoaffinity chromatography with anti-SN AP43 antibodies followed by peptide elution. As shown in Fig. $5 \mathrm{~A}$, the complete recombinant SN AP ${ }_{\mathrm{c}}$ bound efficiently to the wild-type (lanes 4) but not to a mutant (lane 5) PSE. In contrast, proteins present in the control fraction did not bind to either the wild-type or mutant PSE (data not shown). The rSN AP ${ }_{\mathrm{C}}-\mathrm{PSE}$ complex comigrated with the HeLa cell SNAP ${ }_{c}$-PSE complex (lane 2), suggesting that recombinant and biochemically purified SNAP complexes are similar. Addition of antibodies directed against each SNAP ${ }_{c}$ component-SNAP190, SNAP45, SN AP43, SNAP19, or SNAP50-retarded the migration of the rSN AP ${ }_{C}$-PSE complex (lanes 6-10), indicating that each of the five subunits is present in the recombinant SN AP complex.
We have shown previously that independent depletion with anti-SN AP43 (Henry et al. 1995), anti-SN AP45 (Sadowski et al . 1996), anti-SN AP50 (Henry et al . 1996), and anti-SN AP190 (Wong et al. 1998) antibodies inhibits both RNA polymerase II and III snRN A gene transcription, and we have shown above that the same is true for depletions with anti-SNAP19 antibodies. Together, these data suggest that each of these subunits is involved in both RNA polymerase II and III snRNA gene transcription, but they do not address whether the same SNAP complex performs both functions. Therefore, rSNAP $_{c}$ was tested for its ability to reconstitute transcription in vitro, and the results are shown in Figure 5B. $\mathrm{N}$ ucl ear extracts were treated with anti-SN AP43 or preimmune antibody beads and then tested for their ability to support transcription of U 1 snRN A by RNA polymerase II (top panel) and U 6 snRN A by RN A polymerase III (bottom panel). Efficient U 1 and U 6 snRN A transcription was observed in untreated (lane 1) and mock-depleted (lane 2) nucl ear extracts. As expected, treatment with anti-SN AP43 antibody beads greatly diminished both $U 1$ and $U 6$ transcriptional activity (lane 3). Strikingly, upon addition of increasing amounts of the rSN AP $_{c}($ lanes 4,5), but not control fractions (lanes 6,7) to the SNAP ${ }_{\mathrm{c}}$-depleted extract, both U 1 and U 6 transcription were reconstituted efficiently. The levels of transcriptional activity restored by $\mathrm{rSNAP}_{\mathrm{c}}$ were similar to those observed with biochemically purified SNAP ${ }_{C}$ for equivalent 'PSE-binding units' as estimated by EMSA (data not shown). Thus, rSN AP $_{\mathrm{c}}$ assembled from the five core subunits is functional as a basal transcription factor for both the RNA polymerase II and III transcriptional pathways.

rSNAP $_{\mathrm{C}}$ exhibits a similar protein profile as endogenous SNAP

The core SN AP compl ex assembled entirely from recombinant proteins is functional both for DN A binding and transcription of snRNA genes by two different RNA polymerases. To determine the protein profile of rSNAP $_{C}$, a double-tagged rSNAP complex containing His-tagged SNAP190 and HA-tagged SN AP50 was assembled in the baculovirus expression system. As a negative control, an untagged recombinant complex was also assembled. The recombinant complexes were then chromatographed over nickel columns in $350 \mathrm{~mm} \mathrm{KCl}$. Bound proteins were then eluted with imidazole and used di rectly as the starting material for immunopurification with anti-HA antibody beads followed by peptide elution with the HA peptide. As a comparison, endogenous SNAP ${ }_{C}$ was partially purified (mono $S$ step) from HeLa cell S-100 extracts as described previously (Henry et al . 1995). Proteins present in the negative control, the endogenous HeLa SN AP ${ }_{c}$, and the rSN AP $_{c}$ preparations were then size fractionated by SDS-PAGE and visualized by staining with silver.

The negative control fraction did not contain any detectable proteins (data not shown). As shown in Figure 6, the HeLa cell SNAP ${ }_{c}$ preparation, which corresponds to 
Assembly of the basal transcription factor SNAP

A
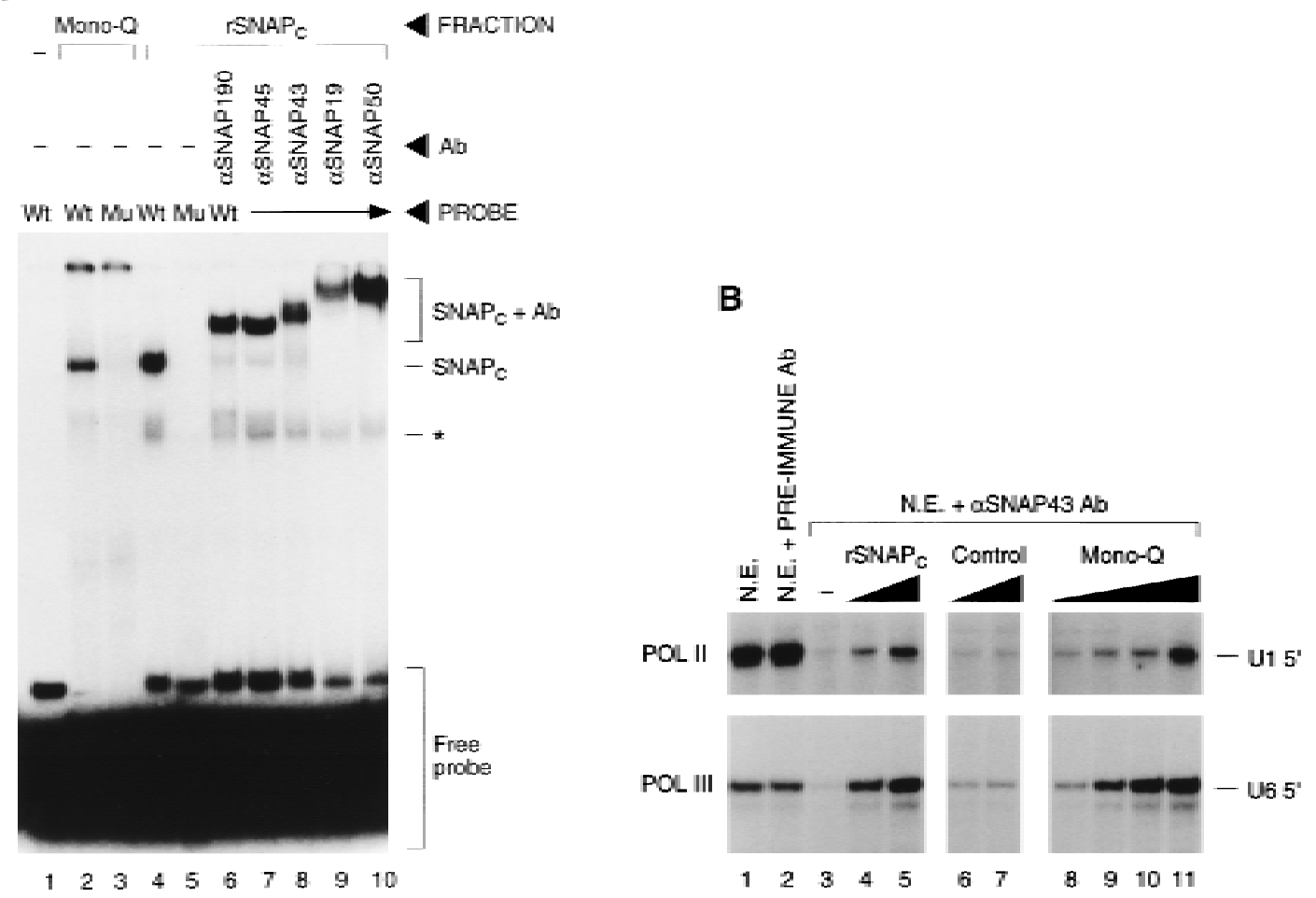

Figure 5. Recombinant core $S N A P_{c}$ binds specifically to the PSE and reconstitutes transcription of the human snRN A genes by RN A polymerase II and III. (A) rSN AP ${ }_{c}$ or partial SN AP complexes missing SN AP190 were assembled by coexpression of the appropriate subunits in a baculovirus expression system and purified by immunoaffinity. The EMSA was performed as described previously (Sadowski et al. 1993) with either wild type (Wt) or mutant (Mu) PSE probe, as indicated above the lanes, and no added fraction (lane

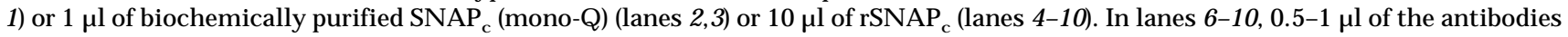
indicated above the lanes was added to the binding reactions. The retarded complexes are label ed $S N A P_{c}+A b$. Preimmune antibodies had no effect on the complex (data not shown). (B) Untreated HeLa nuclear extracts (lane 1) or extracts immunodepl eted with rabbit preimmune (lane 2) or anti-SN AP43 antibody beads (lanes 3-11) were tested for their ability to support in vitro transcription of U 1 snRN A by RNA polymerase II (top panel) and U6 snRNA by RNA polymerase III (bottom panel) as described (Sadowski et al. 1993). In lanes 4 and 5, 5 and $10 \mu \mathrm{l}$ of tagged (top panel) or untagged (bottom panel) rSN AP ${ }_{c}$ was added. In lanes 6 and 7, 5 and $10 \mu l$ of control fractions were added. In lanes $8-11,1,2,4$, and $8 \mu$ l (top panel) or 2, 4, 8, or $16 \mu$ (bottom panel) of biochemically purified SN AP ${ }_{c}$ (mono-Q) were added.

the penultimate step in the purification of $\mathrm{SNAP}_{\mathrm{c}}$ (Henry et al. 1995), still contained a number of proteins, but the individual $\mathrm{SNAP}_{\mathrm{C}}$ subunits (identified by comigration with in vitro-translated, ${ }^{35}$ S $]$ methionine-labeled individual $\mathrm{SNAP}_{C}$ subunits fractionated on the same gel) were visible. In the purified $\mathrm{rSNAP}_{\mathrm{c}}$ preparation, five major bands were visible, four of which either comigrated or migrated close to the HeLa SNAP ${ }_{c}$ subunits (lane 4). However, as expected, the mobility of HAtagged rSN AP50 was reduced as compared to that of untagged HeLa SN AP50. In addition, both RSN AP19 and rSNAP43 migrated slightly differently from the corresponding HeLa SN A $P_{C}$ subunits. These differences may be due to differential post-translational modification of SNAP19 and SNAP43 in the two SNAP preparations. Both of these proteins can be phosphorylated to various extents and, at least in the case of SN AP43, this affects its mobility on SDS-polyacrylamide gels (R.W. Henry, unpubl.). The functional significance of these modifications is, however, not known. These results indicate that al though the natural $\operatorname{SNAP}_{c}$ and the $\operatorname{SSNAP}_{\mathrm{c}}$ are highly similar, they are not identical. However, the subtle differences in migration do not result in functional differences for DNA binding and transcription detectable in our in vitro assays. These results al so show that SN AP19 can be readily identified in both HeLa SN AP ${ }_{C}$ and near homogenous $\operatorname{rSNAP}_{C}$, consistent with the contention that this protein is a bona fide member of the SNAP complex.

\section{Discussion}

Reconstitution of a rSNAP ${ }_{c}$

The identification and cloning of SN AP19 has allowed us to assemble a core $S N A P_{c}$ from recombinant subunits and to describeits architecture. The five $S N A P_{c}$ subunits form a stable complex in which SN A P190 binds strongly and independently to SN AP45 and to SN AP19. The presence of SNAP19 is required for subsequent assembly of SN AP43, which binds to the SN AP190/SNAP19 complex, and SNAP50, which binds to SNAP43. This com- 


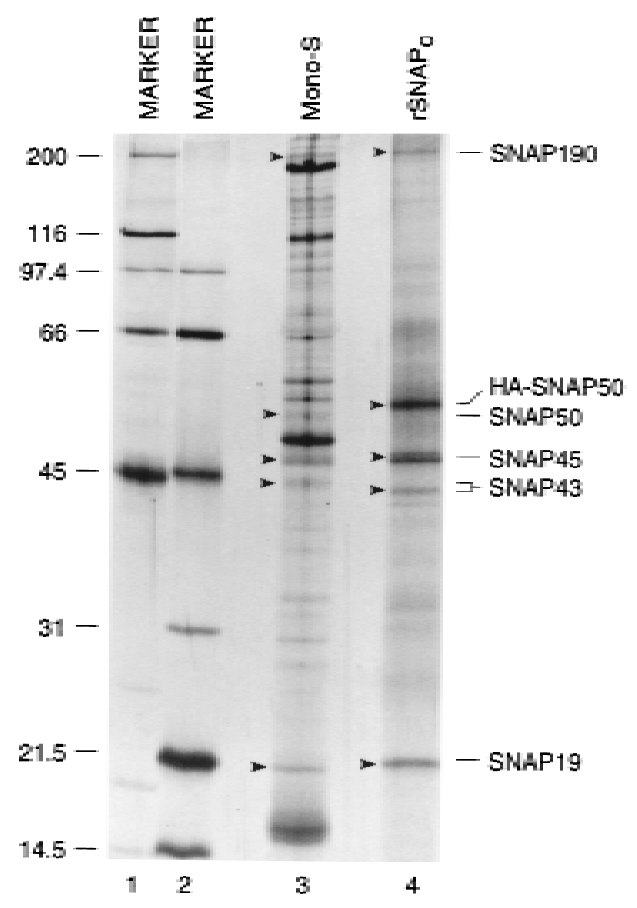

Figure 6. $r S N A P_{c}$ exhibits a similar protein profile as endogenous SN AP ${ }_{c}$. Endogenous $\mathrm{SN} \mathrm{AP}_{c}$ (lane 3) was partially purified from HeLa cell S-100 extracts essentially as described (mono-S stage of purification: Henry et al. 1995). rSN AP $_{c}$ (lane 4) containing His-tagged SN AP190 and HA-tagged SN AP50 was assembled in a baculovirus expression system and purified by chromatography over a nickel column followed by immunopurification with anti-HA antibody beads. Bound proteins were eluted with $400 \mu$ l of buffer D containing the HA peptide (1 $\mathrm{mg} / \mathrm{ml}$ ). The samples were precipitated with TCA and size fractioned by $15 \%$ SDS-PAGE, together with in vitro-translated, $\left[{ }^{35}\right.$ S]methionine-labeled, individual $\mathrm{SN} \mathrm{AP}_{\mathrm{c}}$ subunits as markers (data not shown). Proteins were then visual ized by staining with silver, and the gel was dried and autoradiographed to reveal the location of the radioloabeled $\mathrm{SN} \mathrm{AP}_{\mathrm{C}}$ subunit markers. Arrowheads indicate the location of each $S N A P_{c}$ protein. The identity of each $S N A P_{C}$ subunit is indicated. Lanes 1 and 2 show protein size markers.

plex binds specifically to the PSE. In addition, al though we cannot exclude the possibility of specific contributions by contaminating insect cell proteins, our results show that the core complex is functional for both RNA polymerase II and III transcription of snRN A genes.

Core-promoter recognition by multiprotein complexes is a common theme in transcription, regardless of RN A polymerase specificity. This is probably because multiprotein complexes can effect the control of transcription via di verse programs of protein-protein interactions. For example, the assembly of complete and partial Drosophila TFIID complexes showed that although partial TFIID subcomplexes were active for basal transcription, they responded only to specific subsets of activators in vitro, consistent with the idea that distinct TFIID TAFs are functional ly required for activation in vitro by different activators (Chen et al. 1994). In contrast, for human SL1 and yeast TFIIIB, the same type of experiments showed that all subunits are requi red to obtain transcripti onal ly acti ve complexes (Beckmann et al. 1995; Kassavetis et al. 1995; Roberts et al. 1996; Rüth et al. 1996). It is likely that in the case of SNAP ${ }_{C}$, different subunits perform different functions in RN A polymerase II and III transcription. An exciting possibility is that some subunits are selectively dispensable for transcription by only one of the two RNA polymerases. Because we assembled a rSN $A P_{c}$ from five baculoviruses that each expresses only one of the SNAP ${ }_{c}$ subunits, it will be possible to perform coinfections with subsets of the five viruses and thus assemble partial SN AP complexes that can then be tested for various functions including DN A binding as well as basal and activated RN A polymerase II and III snRN A gene transcription.

How is RNA polymerase specificity determined?

Typically, the basal transcription factors that recognize core promoter elements are dedicated to transcription by distinct RN A polymerases. Thus, the multiprotein complexes SL1, TFIID, TFIIIC, and TFIIIB are specifically required for transcription by RNA polymerases I, II, and III, respectively. Our data presented here suggest that $S N A P_{C}$ is an unusual basal transcription factor in that the very same core complex, consisting of SNAP19, SNAP43, SNAP45, SNAP50, and SNAP190, mediates nucleation of both RNA polymerase II and III SnRNA initiation complexes. This raises the question of how RN A polymerase specificity is determined. The answer likely depends on how TATA box binding protein (TBP) is recruited to the promoter. In our original identification of SNAP $\mathrm{C}_{\mathrm{C}}$, we observed that the complex bound to a PSE could be disrupted with anti-TBP antibodies in an EMSA, suggesting at that time that TBP is a component of $\mathrm{SN} \mathrm{AP}_{\mathrm{C}}$ (Sadowski et al. 1993). We now suspect, however, that this wholesal e disruption reflected proteolytic degradation of the complex by contaminants present in the antibody preparations. Nevertheless, both RNA polymerase II and III transcription of the human SnRNA genes requires TBP (Lobo et al. 1991; Simmen et al. 1991; Sadowski et al. 1993; Yoon and Roeder 1996), and several lines of evidence suggest that core $\mathrm{SN} \mathrm{AP}_{\mathrm{c}}$ can associate with TBP: First, TBP can interact directly with both SN AP43/PTF8 (Henry et al. 1995; Yoon and Roeder 1996) and SN AP45/PTFy (Sadowski et al. 1996; Yoon and Roeder 1996); second, significant (but substoichiometric) amounts of TBP copurify extensively with PSEbinding activity (Henry et al. 1995); third, TBP can be coimmunopreci pitated efficiently from a nucl ear extract with antibodies directed against SNAP43 (Henry et al. 1995) or PTF $\beta /$ SN AP50 (Bai et al. 1996), al though in the latter case, the association with TBP was shown to be salt sensitive, suggesting that TBP associates less tightly with SN AP $\mathrm{C}_{\mathrm{c}}$ PPTF than it does with the TFIID TBP-associated factors (TAFs). Because the RNA polymerase II and III snRNA promoters differ by the absence or presence of a TATA box, it seems likely that different modes of TBP recruitment are key to the determination of RNA polymerase specificity. 
The core SN AP complex likely plays an important role in TBP recruitment to the RNA polymerase II and III snRNA promoters, and we imagine that it can interact with TBP in a flexible manner that accommodates preinitiation compl ex assembly for transcription by the two different polymerases. In the case of RN A polymerase III snRNA promoters, which contain a TATA box at a fixed distance downstream of the PSE, SN AP ${ }_{C}$ binding to the PSE directly recruits TBP to the TATA box, and this effect is dependent on the nonconserved amino-terminal domain of TBP (Mittal and Hernandez 1997). Thus, in this case, TBP (perhaps with additional unidentified factors) is probably recruited to the promoter through a combination of protein-DNA interactions with the TATA box involving the TBP core DNA-binding domain, and protein-protein interactions with $\mathrm{SN} \mathrm{AP}_{\mathrm{C}}$ involving the TBP amino-terminal domain. Which subunit of SN AP ${ }_{C}$ is contacted by the amino-terminal domain of TBP remains to be determined. In the case of RNA polymerase II snRN A promoters, which do not have aTATA box, we have shown that in an extract immunodepleted of TBP, partially purified $\mathrm{SNAP}_{\mathrm{C}}$ fractions (which also contain TBP) restore snRN A gene transcription by RN A polymerase II much more efficiently than recombinant TBP (Sadowski et al. 1993), suggesting that such fractions contain a TBP complex required for RN A polymerase II snRN A gene transcription. Because TBP copurifies with $\mathrm{SNAP}_{\mathrm{c}}$ and interacts with several of its subunits, we suspect that this putative TBP complex is recruited through protein-protein interactions with core SNAP ${ }_{c}$. Thus, the absence or presence of a TATA box in snRN A promoters may direct the same core $\mathrm{SNAP}_{\mathrm{c}}$ to associate with different, RNA polymerase II- or III-specific, TBPcontaining complexes.

\section{Materials and methods}

\section{Immunodepletions and transcription reactions}

The immunoblot in Figure 2A was performed with antibody CS48 (Henry et al. 1995). For the depletions, preimmune or anti-SNAP19 (anti-p19Cpep) antibodies were covalently attached to protein A-Sepharose beads. One hundred microliters of HeLa whole cell extract $(\sim 20 \mathrm{mg} / \mathrm{ml})$ was then incubated with a constant volume of antibody beads $(50 \mu \mathrm{l})$ containing the various ratios of preimmune to anti-SN AP19 antibody beads specified in the legend to Figure 2 . The transcription reactions were performed with $8 \mu \mathrm{l}$ (AdM L), $18 \mu \mathrm{l}$ (U1), $8 \mu \mathrm{l}$ (U6), and $4 \mu \mathrm{l}$ (VAI) of extract as described previously (Sadowski et al. 1993).

\section{Cotranslations and immunoprecipitations}

The coding sequences of SNAP190, SNAP50, SNAP45, SN AP43, and SN AP19 were cloned into the pCite2a vector (Invitrogen). These were used for coupled in vitro transcription/ translation reactions ( $50 \mu \mathrm{l}$ each) in rabbit reticulocyte lysates essentially as described by the manufacturer (Promega). Cotranslation reactions containing all five templates $(\sim 1 \mu \mathrm{g}$ each) were performed. Alternatively, reactions were done in which each template, in turn, was omitted. Ten microliters of each in vitro cotranslation reaction was diluted to $1 \mathrm{ml}$ in HEM GT-150 buffer (20 mM HEPES at pH 7.9; 0.1 mm EDTA, $12.5 \mathrm{~mm} \mathrm{M} \mathrm{gCl}_{2}$,
10\% glycerol, 0.5\% Tween 20; $150 \mathrm{~mm} \mathrm{KCl}$ ) containing protease inhibitors and $3 \mathrm{~mm}$ DTT, and were incubated for $1 \mathrm{hr}$ at room temperature with $10 \mu \mathrm{l}$ of anti-SN AP43 antibody beads. The beads were washed extensively in HEMGT-150 buffer and boiled in Laemmli buffer (Laemmli 1970) to release bound proteins.

Assembly of rSNAP ${ }_{c}$

The coding sequences of SNAP190, SNAP50, SNAP45, SN AP43, and SN AP19 were cloned into a modified baculovirus transfer vector pAcUW51 (Pharmingen) (a kind gift of Paul Kaufman, University of California, Berkeley). In Figure 5, A and B (top), SN AP50 and SN AP45 were expressed as amino-terminal HA epitope fusion proteins while SN AP19 was expressed as a carboxy-terminal HA epitope fusion protein. In Figure 5B (bottom), none of the subunits was tagged. Like tagged rSN AP $_{C}$, untagged $r S N A P_{C}$ bound specifically to the PSE and was active for RNA polymerase II snRNA gene transcription (data not shown). Transfer vectors containing each of the $\mathrm{SNAP}_{c}$ subunits were used to generate recombinant baculoviruses with a BaculoGold transfection kit (Pharmingen). Positive viruses were plaque purified twice and were amplified to a titer of $1 \times 10^{8} \mathrm{PFU} / \mathrm{ml}$. Sf9 cells were infected simultaneously with all five baculoviruses at a multiplicity of infection (m.o.i.) of 10. For the control fraction used in Figure 5 (top), the SN AP190expressing virus was omitted. Cells were harvested $48 \mathrm{hr}$ postinfection, washed, and incubated in lysis buffer $(10 \mathrm{~mm}$ Tris- $\mathrm{HCl}$ at $\mathrm{pH} 7.5 ; 130 \mathrm{~mm} \mathrm{NaCl}, 1 \%$ Triton X-100, $10 \mathrm{~mm} \mathrm{NaF}, 10 \mathrm{~mm}$ $\mathrm{NaPi}, 10 \mathrm{~mm} \mathrm{~N}$ aPPi) on ice for $30 \mathrm{~min}$. $\mathrm{rSN} \mathrm{AP}_{\mathrm{c}}$ was purified by immunoaffinity chromatography and peptide elution.

\section{Purification of $\operatorname{rSNAP}_{\mathrm{c}}$ and silver staining}

rSN AP complexes containing either His-tagged SN AP190 and HA-tagged SN AP50 or only untagged subunits were assembled in a baculovirus expression system essentially as described above. Sf9 cells were lysed as described above, $5 \mathrm{ml}$ of lysate was adjusted to $350 \mathrm{~mm} \mathrm{NaCl}$ and $20 \mathrm{~mm}$ imidazole and incubated with $\mathrm{Ni}$-NTA agarose beads (Qiagen) for $2 \mathrm{hr}$ at $4^{\circ} \mathrm{C}$. Bound proteins were eluted with the same buffer containing $300 \mathrm{~mm}$ imidazole and used directly for immunopurification with a 7:1 ( $\mathrm{vol} / \mathrm{vol}$ ) ratio of sample to protein G-Sepharose beads (Boehringer Mannheim) covalently coupled to anti-HA antibodies. Bound proteins were el uted twice with $200 \mu$ l of buffer containing 20 mM HEPES (pH 7.5), 15\% glycerol, 0.1\% Tween 20, 5 mm $\mathrm{M} \mathrm{gCl}_{2}, 100 \mathrm{mM} \mathrm{KCl}, 0.5 \mathrm{~mm}$ PMSF, $2 \mathrm{~mm} \mathrm{DTT}$, and $0.7 \mathrm{mg} / \mathrm{ml}$ HA peptide. The eluates were pooled and precipitated with TCA. Proteins present in the doubletagged $\mathrm{SSN} \mathrm{AP}_{\mathrm{C}}$, untagged $\mathrm{rSNAP}_{\mathrm{c}}$, and HeLa SNAP $\mathrm{P}_{\mathrm{c}}$ fractions were separated by $15 \%$ SDS-polyacrylamide gels al ongside in vitro-translated, $\left.{ }^{35} \mathrm{~S}\right] \mathrm{me}-$ thionine-labeled, individual SN AP ${ }_{c}$ subunits. Proteins were visualized by staining with silver, and then the gel was dried and autoradiographed to reveal the location of the radioloabeled SN AP ${ }_{C}$ subunits.

\section{Acknowledgments}

We thank MeeWa Wong, Viola Ellison, and Paul Kaufman for hel $p$ with the baculovirus expression system, Spencer Tepl in for oligonucleotide synthesis, and James Duffy, Michael Ockler, and Philip Renna for artwork and photography. We also thank Winship Herr, Cyril Sanders, and Grace Chen for discussion and comments on the manuscript. This work was funded in part by $\mathrm{N}$ ational Institutes of Heal th grant GM 38810. R.W.H. was supported by the Joseph G. Goldring Foundation. 
The publication costs of this article were defrayed in part by payment of page charges. This article must therefore be hereby marked 'advertisement' in accordance with 18 USC section 1734 solely to indicate this fact.

\section{References}

Bai, L., Z. Wang, J.-B. Yoon, and R.G. Roeder. 1996. Cloning and characterization of the $\beta$ subunit of human proximal se quence el ement-binding transcription factor and its involvement in transcription of small nuclear RNA genes by RN A polymerases II and III. Mol. Cell. Biol. 16: 5419-5426.

Beckmann, H., J.-L. Chen, T. O'Brien, and R. Tjian. 1995. Coactivator and promoter-selective properties of RNA polymerase I TAFs. Science 270: 506-1509.

Chen, J.-L., L.D. Attardi, C.P. Verrijzer, K. Yokomori, and R. Tjian. 1994. Assembly of recombinant TFIID reveals differential coactivator requirements for distinct transcriptional activators. Cell 79: 93-105.

Dahl berg, J.E. and E. Lund. 1988. The genes and transcription of the major small nuclear RN As. In Structure and function of major and minor small nuclear ribonucleoprotein particles (ed. M.L. Birnstiel), pp. 38-70. Springer Verlag, Berlin, Germany.

Geiduschek, E.P. and G.A. Kassavetis. 1992. RNA polymerase III transcription complexes. Transcriptional regulation (ed. S.L. McKnight and K.R. Yamamoto), pp. 247-280. Cold Spring Harbor Laboratory Press, Cold Spring Harbor, NY.

Henry, R.W., C.L. Sadowski, R. Kobayashi, and N. Hernandez. 1995. A TBP-TAF complex required for transcription of human snRN A genes by RNA polymerases II and III. Nature 374: 653-657.

Henry, R.W., B. Ma, C.L. Sadowski, R. Kobayashi, and N. Hernandez. 1996. Cloning and characterization of SNAP50, a subunit of the snRNA-activating protein complex SNAPC. EMBO J. 15: 7129-7136.

Kassavetis, G.A., S.T. N guyen, R. Kobayashi, A. Kumar, E.P. Geiduschek, and M. Pisano. 1995. Cloning, expression, and function of TFC5, the gene encoding the $B^{\prime \prime}$ component of the Saccharomyces cerevisiae RN A polymerase III transcription factor TFIIIB. Proc. Natl. Acad. Sci. 92: 9786-9790.

Laemmli, E.K. 1970. Cleavage of structural proteins during assembly of the head of bacteriophage T4. Nature 227: 680685.

Lobo, S. and N. Hernandez. 1989. A 7 bp mutation converts a human RNA polymerase II snRNA promoter into an RNA polymerase III promoter. Cell 58: 55-67.

Lobo, S.M., J. Lister, M.L. Sullivan, and N. Hernandez. 1991. The cloned RNA polymerase II transcription factor IID se lects RN A polymerase III to transcribe the human U 6 gene in vitro. Genes \& Dev. 5: 1477-1489.

M attaj, I.W., N .A. Dathan, H.W. Parry, P. Carbon, and A. Krol 1988. Changing the RNA polymerase specificity of $U$ snRN A gene promoters. Cell 55: 435-442.

Mittal, V. and N. Hernandez. 1997. Role for the amino-terminal region of human TBP in U 6 snRN A transcription. Science 275: 1136-1140.

M urphy, S., J.-B. Yoon, T. Gerster, and R.G. Roeder. 1992. Oct-1 and Oct-2 potentiate functional interactions of a transcription factor with the proximal sequence element of small nuclear RN A genes. Mol. Cell. Biol. 12: 3247-3261.

Orphanides, G., T . Lagrange, and D. Reinberg. 1996. The general transcription factors of RNA polymerase II. Genes \& Dev. 10: 2657-2683.

Roberts, S., S.J. Miller, W.S. Lane, S. Lee, and S. Hahn. 196. Cloning and functional characterization of the gene encod- ing the TFIIIB90 subunit of RNA polymerase III transcription factor TFIIIB. J. Biol. Chem. 271: 14903-14909.

Rüth, J., C. Conesa, G. Dieci, O. Lefebvre, A. Düsterhöft, S. Ottonello, and A. Sentenac. 1996. A suppressor of mutations in the class III transcription system encodes a component of yeast TFIIIB. EMBO J. 15: 1941-1949.

Sadowski, C.L., R.W. Henry, S.M. Lobo, and N. Hernandez. 1993. Targeting TBP to a non-TATA box cis-regulatory element: A TBP-containing complex activates transcription from snRNA promoters through the PSE. Genes \& Dev. 7: $1535-1548$

Sadowski, C.L., R.W. Henry, R. Kobayashi, and N. Hernandez. 1996. The SNAP45 subunit of the small nuclear RNA (snRNA) activating protein complex is required for RNA polymerase II and III snRN A gene transcription and interacts with the TATA box binding protein. Proc. Natl. Acad. Sci. 93: 4289-4293.

Simmen, K.A., J. Bernues, H.D. Parry, H.G. Stunnenberg, A. Berkenstam, B. Cavallini, J.-M. Egly, and I.W. Mattaj. 1991 TFIID is required for in vitro transcription of the human U6 gene by RN A polymerase III. EMBO J. 10: 1853-1862.

Wong, M.W., R.W. Henry, B. Ma, R. Kobayashi, N. Klages, P. Matthias, M. Strubin, and N. Hernandez. 1998. The large subunit of basal transcription factor $\mathrm{SN} \mathrm{AP}_{\mathrm{C}}$ is a M yb domain protein that interacts with Oct-1. Mol. Cell. Biol. 18: 368377.

Yoon, J.-B. and R.G. Roeder. 1996. Cloning of two proximal sequence element-binding transcription factor subunits $(\gamma$ and $\delta$ ) that are required for transcription of small nuclear RN A genes by RN A polymerases II and III and interact with the TATA-binding protein. Mol. Cell. Biol. 16: 1-9.

Yoon, J.-B., S. M urphy, L. Bai, Z. Wang, and R.G. Roeder. 1995. Proximal sequence element-binding transcription factor (PTF) is a multisubunit complex required for transcription of both RNA polymerase II- and RNA polymerase III-dependent small nuclear RNA genes. Mol. Cell. Biol. 15: 20192027. 


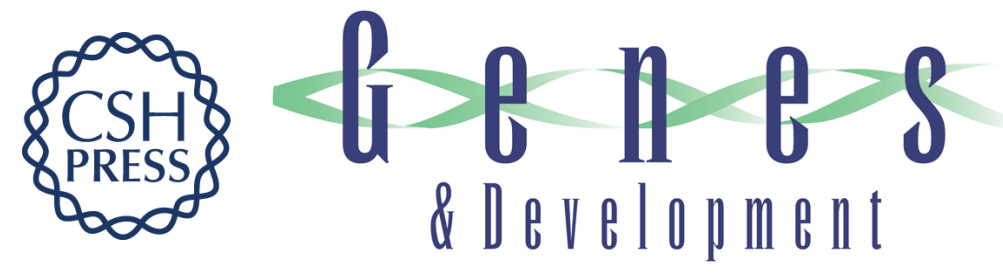

\section{SNAP19 mediates the assembly of a functional core promoter complex (SNAP $\mathrm{c}$ ) shared by RNA polymerases II and III}

R. William Henry, Vivek Mittal, Beicong Ma, et al.

Genes Dev. 1998, 12:

Access the most recent version at doi:10.1101/gad.12.17.2664

References

This article cites 21 articles, 11 of which can be accessed free at: http://genesdev.cshlp.org/content/12/17/2664.full.html\#ref-list-1

License

Email Alerting

Receive free email alerts when new articles cite this article - sign up in the box at the top Service right corner of the article or click here.

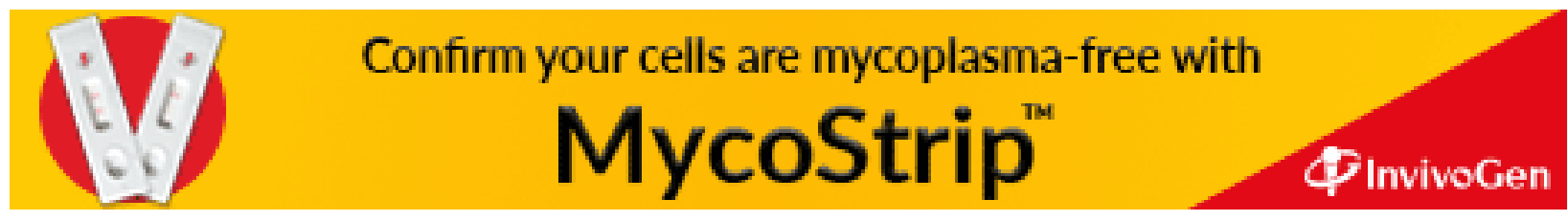

